clusion is that the intensities of all the lines were nearly proportional to the mass of air traversed. The lines $6868(B), 6517$, $6278(\alpha)$, and $5800(\delta)$ were practically of the same intensity, for equal masses of air, at all the three observing stations, showing that the presence of water-vapour had little or no influence on them, and indicating that their origin was most probably atmospheric oxygen. The rain-band line (5943), however, has, for equal masses of air, a much less (about one-third) intensity at Etna than at the other two stations. The mean vapour tensions at the three places, Etna, Nicolosi, and Catania, were as $3: 7:$ Io, so that this line 5943 is evidently due to aqueous vapour. The fact that when the observations are plotted the curves pass through or near the origin, indicates that the atmospheric oxygen and water-vapour are the sole causes of these telluric lines.

Explanation of Solar Phenomena.-In the June number of the Astro Physical Journal, J. Fényi discusses several new explanations of the various features of the solar surface, emphasising several physical facts, hitherto neglected, the consideration of which simplify the conception of the causes of the solar phenomena. He assumes that the prominences are masses of real matter in violent motion, and also that they are ejected into free space. The crucial point of his argument is that when a mass of hydrogen, say, is projected from the photosphere, and has passed through the chromosphere into free space, it is not diffused immediately, but takes a certain time, termed the expansion interval, which varies directly as the diameter of the mass, and is inversely proportional to the square root of the absolute temperature. By following out in detail the phenomena of eruptive prominences, he explains them all on this view, especially their unusual brightness and rapid dissolution. The white prominences he accounts for as being the expanded gaseous portions of former ordinary prominences, rendered visible by reflected sunlight. The corona he regards as being due to more distant masses of these gaseous materials, primarily ejected as prominences, the enormous length of some coronal streamers being no difficulty if they are admitted to be projected in free space. Faculce will then be produced by these gaseous matters falling down on the photosphere again, their superior brightness being due to the heat generated during their fall, together with the actual radiation received from the sun itself. Their prevalence in sun-spot zones is explained if they are the consequence of eruptive prominences, which themselves favour these zones. This dispenses with the view that faculæ are projected prominences, and regards them as the result of prominence action. The much-disputed question of the reason of distorted spectral lines in prominences is greatly simplified by this explanation. If a mass of ascending gas as a prominence encounters a descending mass from a previous eruption, the resultant motion will in general be tangential to the solar surface, and will be capable of producing the enormous velocities in the line of sight which have been measured in prominence spectra, and which could not be explained as being the result of mere explosions from the photosphere.

\section{NEW FORM OF APPARATUS FOR THE PRODUCTION OF RÖNTGEN RAYS.}

SOME time in the month of March this year, after working with various forms of tubes, it occurred to the writer to abolish the glass vessel by converting the ordinary concave kathode into a nearly complete sphere, with the platinum anode at its centre. A simple experiment with a Jackson bulb proved that the rays from the anode could pass through the material of the kathode as they would through a similar piece of unelectrified aluminium placed outside the bulb. Hence it became fairly evident at the outset that the proposed plan would work to some extent.

Under the guidance of Prof. Lodge, and in his research laboratory, experiments were commenced. The first arrangement was a simple one. The sphere was made in two halves, one half of copper and the other of aluminium. The two halves were joined together with marine glue only. The anode was held in position by ebonite fixed in the copper hemisphere. A section of this simple arrangement is shown in Fig. 1 . The section is drawn to scale, the diameter of the sphere being 2 inches. This early apparatus showed signs of success, and it was decided to invest in a larger sphere--one of $3 \frac{1}{2}$ inches in diameter. The joints were now made much more carefully, and the apparatus so designed that it could be fitted together or taken to pieces in half an hour's time. The hemispheres of copper and aluminium were soldered together, but the joints ( $\mathrm{A}$ and $\mathrm{B}$, Fig. I) were made by compressing indiarubber washers by means of suitably made screws. With this convenient apparatus the behaviour of various sizes and shapes of anodes was observed. In all the experiments a small thick plate of platinum, having a plane surface of about $\frac{1}{4}$ square inch, was reserved for that portion of the anode which received the kathode rays; the remainder of the anode was sometimes of aluminium and sometimes of copper. The various forms tried are shown in Figs. 2 to 8.

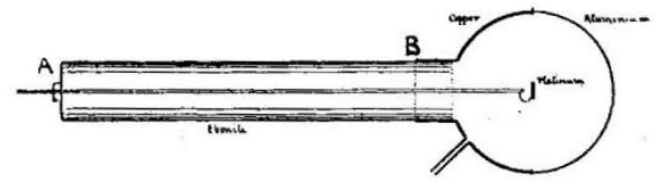

Fig 1

In Fig. 2 we have the simplest possible anode-the platinum plate alone. It is the same arrangement as that of Fig. I, the only difference being that of dimensions. This form possessed an enormous resistance, so that only with low vacua could a current be made to pass through. For this reason the behaviour of this form was unsteady and its periods of activity very short. With higher vacua and greater potentials, no doubt this form would be more successful. Another form tried was that shown in Fig. 3. The anode here was very considerably enlarged by placing a circular plate of metal just behind the platinum, at a place where no kathode rays could fall on it By this means the area of the anode surface was increased sixteen-fold approximately. The resistance was thereby much reduced, and it became possible to work at higher vacua. This form gave a more powerful and a considerably more uniform radiation than that of its predecessor.

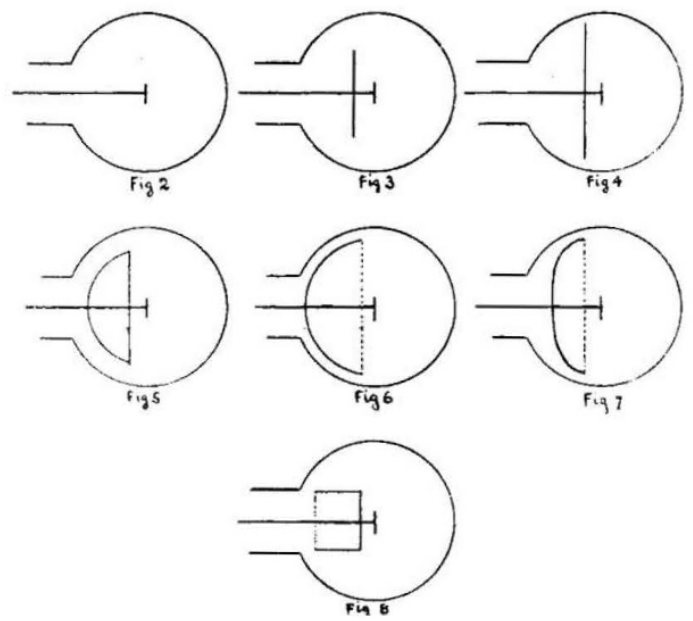

The next step was to increase still further the area of the anode (see Fig. 4). The anode now nearly filled the sphere. The result, however, was not so good, tending to show that the best size of anode is something less than Fig. 4, and greater than Fig. 2; but Prof. Lodge thinks that this is a question of the particular vacuum employed. Another differently-shaped anode was next tried. This was formed of a metallic hemisphere with a flat plate in front of it (see Fig. 5). The idea was to get all, or nearly all, of the electric discharge, and so possibly most of the kathode radiation also, to take place between the outer aluminium hemisphere and the anode. The idea probably is a crooked one; anyhow, this form proved less successful than others. The plate was next removed, and the hemisphere was replaced by a larger one, as in Fig. 6 . For some unknown reason this form gave no radiation whatever, although the NO. I 395 , VOL. 54] 
vacuum was fairly high. The resistance, however, was low. The experiment was not really a successful one, for there arose some trouble from either small leakages or vapour pressures. The next form was Fig. 7. This gave really bright flashes on a sensitive screen, and the resistance was low. Still another form is that of Fig. 8. The anode now is a hollow cylinder with one end open. The total area of this anode is considerably greater than that of Fig. 3, but the latter gave much the more powerful radiation. It appears, therefore, that both the size and the shape of the anode have an important influence on the radiating power of the apparatus.

The form which gave the most powerful radiation was that of Fig. 3. This sent a powerful radiation through 3 feet of solid timber. The rays on emerging were received on a fluorescent screen made of about fifteen shillings' worth of potassium-platino-cyanide, and the area of which was 36 square inches. This screen was considerably affected by the rays after having traversed the 3 feet of timber, and gave sufficient light to see very small objects in. But the hand, when placed between the screen and the timber, cast no shadow whatever.

The next observation on the power of the radiation was to take the screen to a distance of 30 feet from the source. At this distance the bones of the hand could be seen, but not the flesh. Even the bones cast no deep and sharp shadows at this distance, not owing to lack of fluorescence--for the screen was really bright-but owing probably to the turbidity of the intervening 30 feet of air.

The source was afterwards placed in position at one end of the laboratory, and the screen taken to the opposite end, or facturing the various parts. The parts are easily enough made, but manufacturers seldom care to attend to single articles except at their own convenience.

In conclusion it may be stated, though it is unnecessary to do so, that the instrument just described owes its existence to the teaching of Prof. Lodge.

Benjamin Davies.

\section{THE ROBOROVSKY EXPEDITION.}

ROBOROVSKY and Kozloff, the two explorers who accompanied Prjevalsky in his last journeys, and for two years continued his work of exploration of Central Asia, are now back at St. Petersburg; and they have returned literally loaded with zoological, botanical, and geological collections, together with the results of meteorological observations and extensive surveys, as well as of numerous astronomical determinations. The chief interest of the collections will certainly be centred round the specimens of the wild horse (Equus Przewalskii) and wild camel which they have secured, as well as in the great numbers of new species of plants and insects which have been systematically collected by M. Kurilovitch, who stayed at well-chosen stations, while Roborovsky and Kozloff, mostly accompanied by one man only, made the most adventurous "excursions"-that is, journeys three and four hundred miles long-into the unknown highlands of the NanShan. Great privations were endured by the two explorers during these journeys, which were made without guides, during the winter, when the thermometer stood at $-25^{\circ}$ to $-35^{\circ} \mathrm{C}$., and fearful snow-storms blew away the tent, while the sand borne

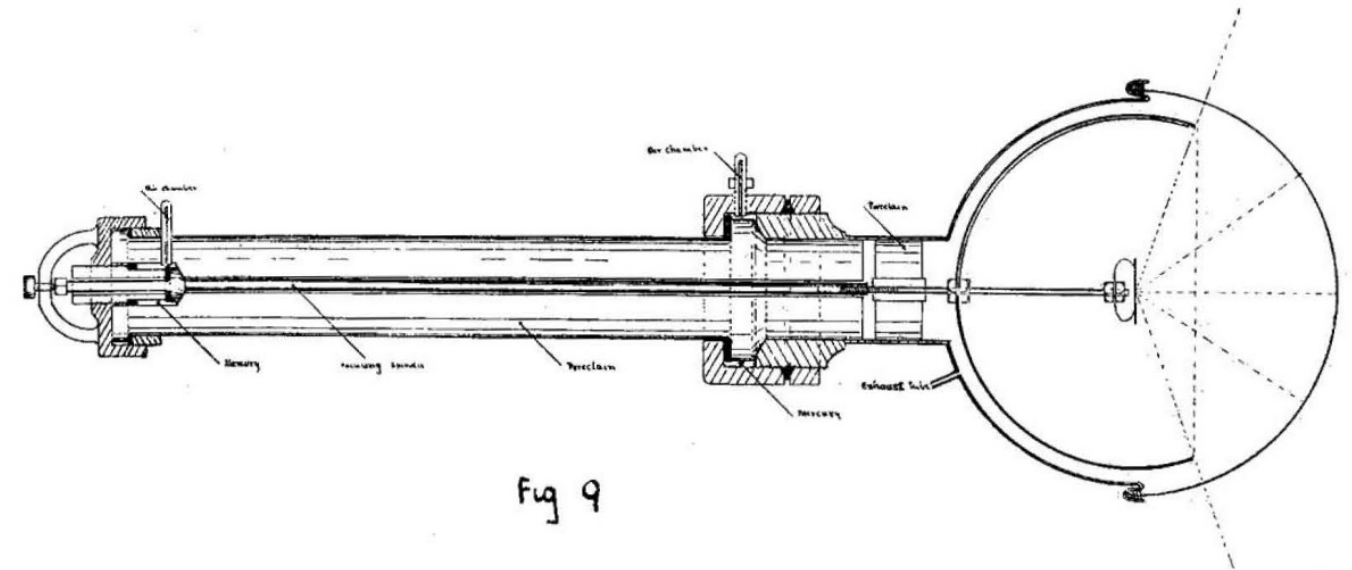

rather to the end of the corridor leading to the laboratory-a distance of 62 feet from the source. Even here the screen fluoresced with some energy, but the hand was observed to cast no perceptible shadow. When this apparatus was working, there was no place within the large room where the screen did not fluoresce, the rays passing through masses of timber and tables with surprising penetration.

This experimental tube, however, with its rubber joints and ebonite insulation, is not a lasting concern. Although a good vacuum can be maintained for hours together when not in work, it will not last more than half an hour or so when in continuous use, after which more pumping is necessary. The current evidently produces some change in the rubber and ebonite, disengaging a gas which slowly destroys the vacuum.

In the final instrument the joints are of mercury, and the insulation of porcelain. The joints are first ground and polished, and then flooded with mercury. Except the porcelain, the entire apparatus can be made in the lathe, which is a great consideration. A longitudinal section of the instrument is given in Fig. 9. At the end of the porcelain is an arrangement for focusing, which can be manipulated while the instrument is working, so that a point source can be obtained definitely and easily by trial. This figure, which is reproduced from an early picture, has a spherical anode. This should be replaced by a circular plate resembling the anode of Fig. 3 .

This last form of instrument, though designed in the middle of May, has not yet been built, owing to the delay in manu. NO. I 395, , VOL. 54] by the wind sharply stung the travellers' frozen faces. These privations, of which the Russian travellers speak so lightheartedly, seem, however, to have ruined the health of the chief of the expedition, Roborovsky. And when the expedition made its last journey into the highlands which separate the Nan-Shan highlands from the valley of the Yellow River, Roborovsky, who had already endured pleurisy and erysipelas, was laid down with a stroke of paralysis, which deprived him of the use of all the right part of his body; while the Tangut robbers, who people these mountains, gathered in bands round the small encampment. The expedition was already at the western foot of the high snow-clad chain of peaks of the Alma-machin, which rise on the left bank of the famous bending of the Yellow River; a few days' journey only separated them from the yellow waters of the Hoang-ho; but in such conditions they were compelled to return-the Tanguts immediately taking advantage of the retreat to attack the caravan. They were only repulsed, Roborovsky writes, after "a great loss in men and horses."

Notwithstanding this failure, even the purely geographical results of the expedition, to say nothing of its scientific collections, are very important. From Lake Issyk-Kul the small party proceeded eastwards, exploring the highlands and the plateau of Yulduz, to Karashar, near Lake Denghiz, or Bagrach-Kul, and thence to Turfan and the oasis of Hami. Having now to cross the great desert of the Hashun Gobi, before reaching the Nan-Shans, Roborovsky and Kozloff took 